\title{
ANALISIS ALGORITMA ROUND ROBIN, LEAST CONNECTION, DAN RATIO PADA LOAD BALANCNG MENGGUNAKAN OPNET MODELER
}

\author{
Husain Nasser ${ }^{1}$ \\ husainnassr@gmail.com
}

\author{
Timotius Witono ${ }^{2}$ \\ timotius@itmaranatha.org
}

\begin{abstract}
Load balancing is a technique to distribute traffic load into two or more lanes to reach balanced connection, optimized traffic performance, maximized data throughput, minimized delay, and avoiding data overload. Load balancing in a computer network used to modulate the balance of bandwidth usage between multiple internet service provider. This research contains Load Balancing performance test on HTTP, FTP, and VoIP. Testing application used is OPNET Modeler 14.5 simulator, and load balancing algorithm which being tested is Least Connection, Round Robin, and Ratio. The test results shows generally Ratio is better than Least Connection and Round Robin. Ratio excels on handling End-to-End Delay and Jitter in VoIP, while Least Conncetion shows the highest throughput value in all test cases.

Keywords: load balancing, round robin, least connection, ratio, OPNET modeler
\end{abstract}

\section{Pendahuluan}

Internet Service Provider (ISP) menyediakan layanan internet, baik untuk sambungan internet lokal maupun internasional. Sambungan lokal menyediakan interkoneksi antar ISP yang terdapat di Indonesia agar dapat saling terhubung satu sama lain, sedangkan sambungan internasional menyediakan bandwidth yang dapat digunakan untuk terhubung ke backbone internasional. Bandwidth adalah besaran yang menunjukkan seberapa banyak data yang dapat dilewatkan dalam koneksi melalui sebuah network (Haryadi, 2010).

Kebutuhan bandwidth internet semakin hari semakin meningkat, sehingga seringkali dibutuhkan penggunaan layanan internet dari beberapa ISP sekaligus. Sebuah perusahaan dapat menambahkan jalur internet secondary, jika merasa jalur internet primary tidak dapat menampung kebutuhan penggunaan bandwidth secara maksimal. Pembagian penggunaan masing-masing jalur internet dapat diatur sesuai kebutuhan dan karakteristik pengguna. Penggunaan jalur-jalur internet juga dapat dimaksimalkan dengan penerapan teknik load balancing.

Load balancing adalah sebuah teknik mendistribusikan beban traffic pada dua jalur atau lebih, sehingga didapatkan sambungan yang seimbang, traffic yang lebih optimal, throughput data maksimal, delay minimal, serta tidak terjadi overload. Load balancing dapat diimplementasikan pada perusahaan yang memiliki minimal dua sambungan internet. Penelitian terkait menyatakan bahwa beban jaringan tidak menjadi lebih ringan dengan adanya load balance, akan tetapi load balance bertugas sebagai pengatur alokasi beban jaringan (Saputra, 2013). "Load balancing algoritma bekerja pada prinsip bahwa situasi di mana beban kerja diberikan, selama waktu kompilasi atau pada runtime. Perbandingan menunjukkan bahwa algoritma beban statis balancing lebih stabil dibandingkan dengan dinamis dan juga kemudahan untuk memprediksi perilaku statis, tetapi pada saat yang sama algoritma terdistribusi yang dinamis selalu dianggap lebih baik daripada algoritma statis" (Kurniawan, 2011).

\section{Dasar Teori}

\subsection{Algoritma Load Balancing}

Load balancing adalah sebuah konsep yang berguna untuk menyeimbangkan beban atau muatan dalam jaringan komputer, makin besar traffic data yang ada dalam jaringan komputer

\footnotetext{
${ }^{1}$ Program Studi S1 Teknik Informatika, Fakultas Teknologi Informasi, Universitas Kristen Maranatha, Bandung

${ }^{2}$ Program Studi S1 Teknik Informatika, Fakultas Teknologi Informasi, Universitas Kristen Maranatha, Bandung
} 
maka semakin berat pengaksesannya. Layanan load balancing memungkinkan pengaksesan sumber daya dalam jaringan didistribusikan ke beberapa host, agar tidak terpusat, sehingga kinerja jaringan komputer menjadi lebih stabil (Kopparapu, 2002).

Proses pembagian beban pada sistem load balancing memiliki teknik dan algoritma tersendiri. Perangkat load balancing yang kompleks biasanya menyediakan berbagai teknik dan algoritma pembagian beban ini, tujuannya untuk menyesuaikan pembagian beban dengan karakteristik dari masing-masing pengguna internet. OPNET memungkinkan peneliti untuk membuat simulasi jaringan komputer yang melibatkan berbagai unsur teknologi jaringan yang ada, termasuk load balancing (OPNET, 2012).

\subsection{Round Robin}

Algoritma Round Robin merupakan algoritma yang paling sederhana dan paling banyak digunakan oleh perangkat load balancing. Algoritma Round Robin bekerja dengan cara membagi beban secara bergiliran dan berurutan dari satu server ke server lainnya. Konsep dasar dari algoritma Round Robin ini adalah dengan menggunakan time sharing, pada intinya algoritma ini memproses antrian secara bergiliran (Ellrod, 2010).

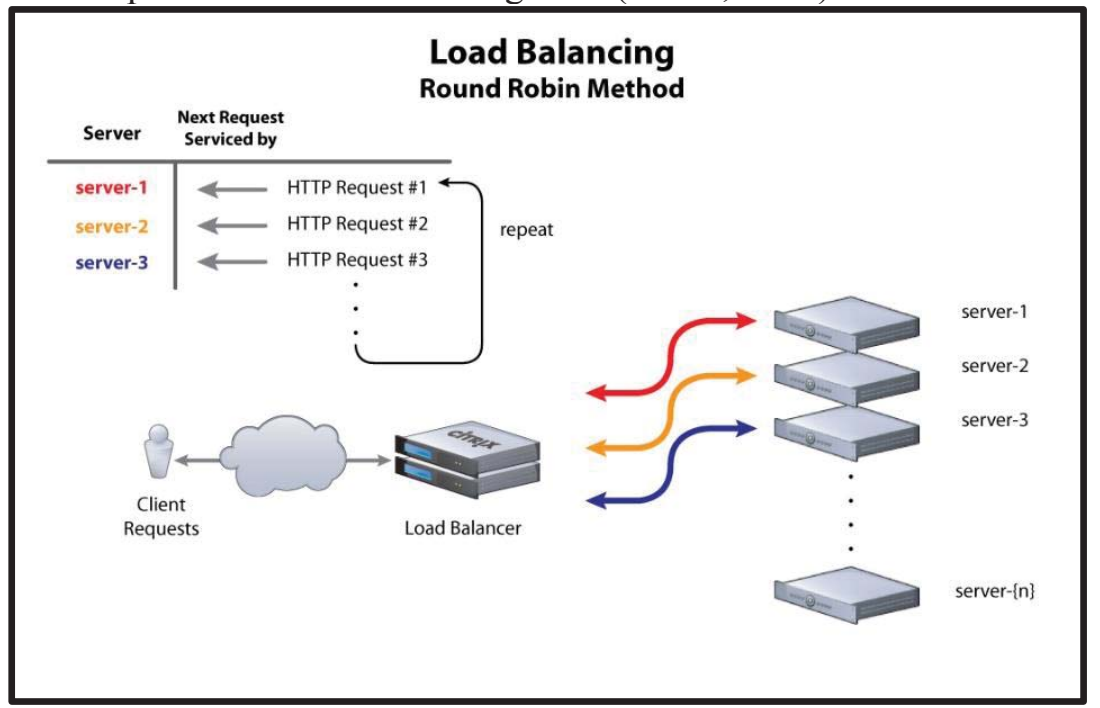

\subsection{Least Connetion}

Gambar 1. Proses Round Robin (Ellrod, 2010)

Algoritma Least Connection melakukan pembagian beban berdasarkan banyaknya koneksi yang sedang dilayani oleh sebuah server. Server dengan koneksi yang paling sedikit akan diberikan beban berikutnya, begitu pula server dengan koneksi banyak akan dialihkan bebannya ke server lain yang bebannya lebih rendah (Ellrod, 2010).

Penjadwalan ini termasuk salah satu algoritma penjadwalan dinamik, karena memerlukan perhitungan koneksi aktif untuk masing-masing real server secara dinamik. Metode penjadwalan ini baik digunakan untuk melancarkan pendistribusian ketika request yang datang sangat banyak. Sebagai contoh terdapat dua Service-HTTP yaitu Service HTTP-1 (terdapat 3 active HTTP transaction) dan Service HTTP 2 (terdapat 1 active HTTP transaction), maka Service HTTP-2 akan menerima request selanjutnya dikarenakan Service HTTP-1 > Service HTTP-2 pada nilai transaksi aktifnya. 


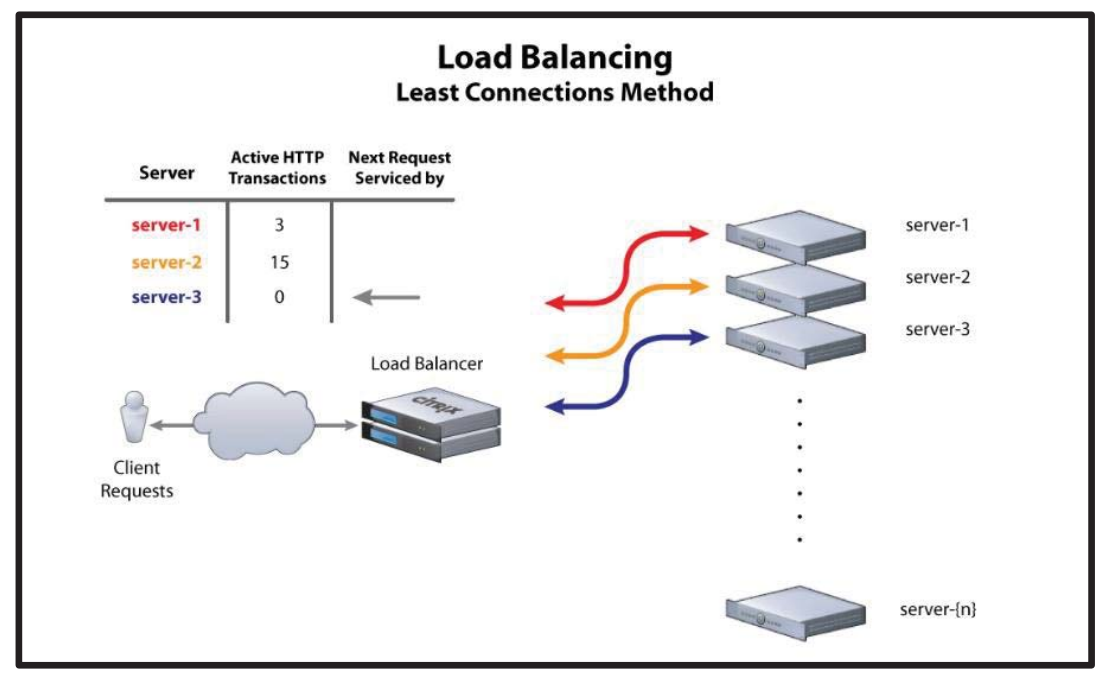

\subsection{Ratio}

Gambar 2. Proses Least Connections (Ellrod, 2010)

Ratio menggunakan parameter ratio pada masing-masing server di dalam sistem load balancing. Parameter ratio ini akan menjadi landasan pembagian beban pada server-server yang terlibat. Server dengan ratio terbesar diberi beban besar, sebaliknya server ratio kecil akan lebih sedikit diberi beban (DELL inc, 2015).

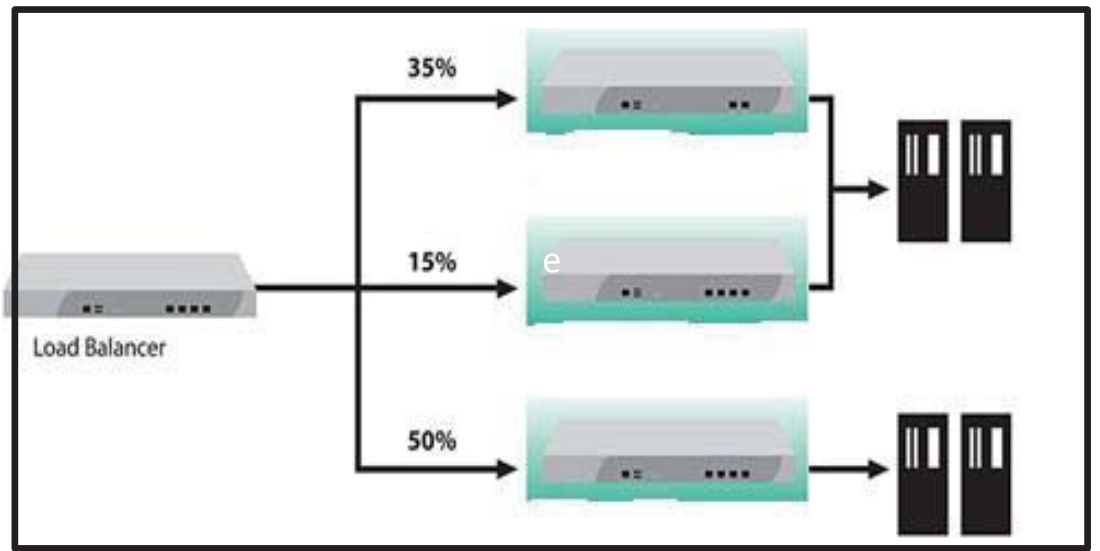

Gambar 3. Proses Ratio (DELL inc, 2015)

\subsection{Pengukuran Kinerja Jaringan}

Quality of Service (QoS) merupakan kemampuan jaringan untuk menyediakan service yang lebih baik untuk traffic tertentu dari berbagai macam teknologi seperti jaringan IP, frame relay, ATM dan SDH. Elemen QoS tergantung dari informasi yang ditransmisikan (voice, data atau video) (Anton, 1997) (Haryadi, 2010). Beberapa faktor yang mempengaruhi QoS pada jaringan IP:

\section{Throughput}

Throughput adalah jumlah bit yang diterima dengan sukses per detik melalui sebuah sistem atau media komunikasi (kemampuan sebenarnya suatu jaringan dalam melakukan pengiriman data). Throughput dapat diukur setelah transmisi data dilakukan, karena suatu sistem akan menambah delay yang disebabkan processor limitations, buffering inefficients, error transmission, traffic loads dan lain-lain. Aspek utama throughput berkisar pada ketersediaan bandwidth yang cukup untuk menjalankan aplikasi.

\section{Jitter}

Jitter adalah variansi delay, yaitu perbedaan selang waktu kedatangan antar paket di terminal tujuan. Untuk mengatasi jitter maka paket data yang datang dikumpulkan dulu dalam jitter buffer selama waktu yang telah ditentukan sampai paket dapat diterima pada sisi penerima dengan urutan yang benar. 


\section{Delay}

Delay adalah waktu tunda paket yang diakibatkan oleh proses transmisi dari satu titik lain yang menjadi tujuannya. Ada dua penyebab terjadinya delay dalam jaringan, yaitu Fixed Delay dan Variable Delay.

\section{Analisis dan Perancangan Jaringan}

\subsection{Topologi Jaringan}

Simulasi jaringan load balancing menggunakan 3 buah workstation yang terhubung ke switch, kemudian switch terhubung ke router. Sebelum terhubung ke internet, jaringan terhubung ke ISP-1 dan ISP-2, lalu terhubung ke internet dan melewati firewall. Secara keseluruhan jaringan akan memampukan seluruh workstation (node client) untuk dapat terhubung ke DB server, VoIP server, HTTP server, ataupun FTP server.

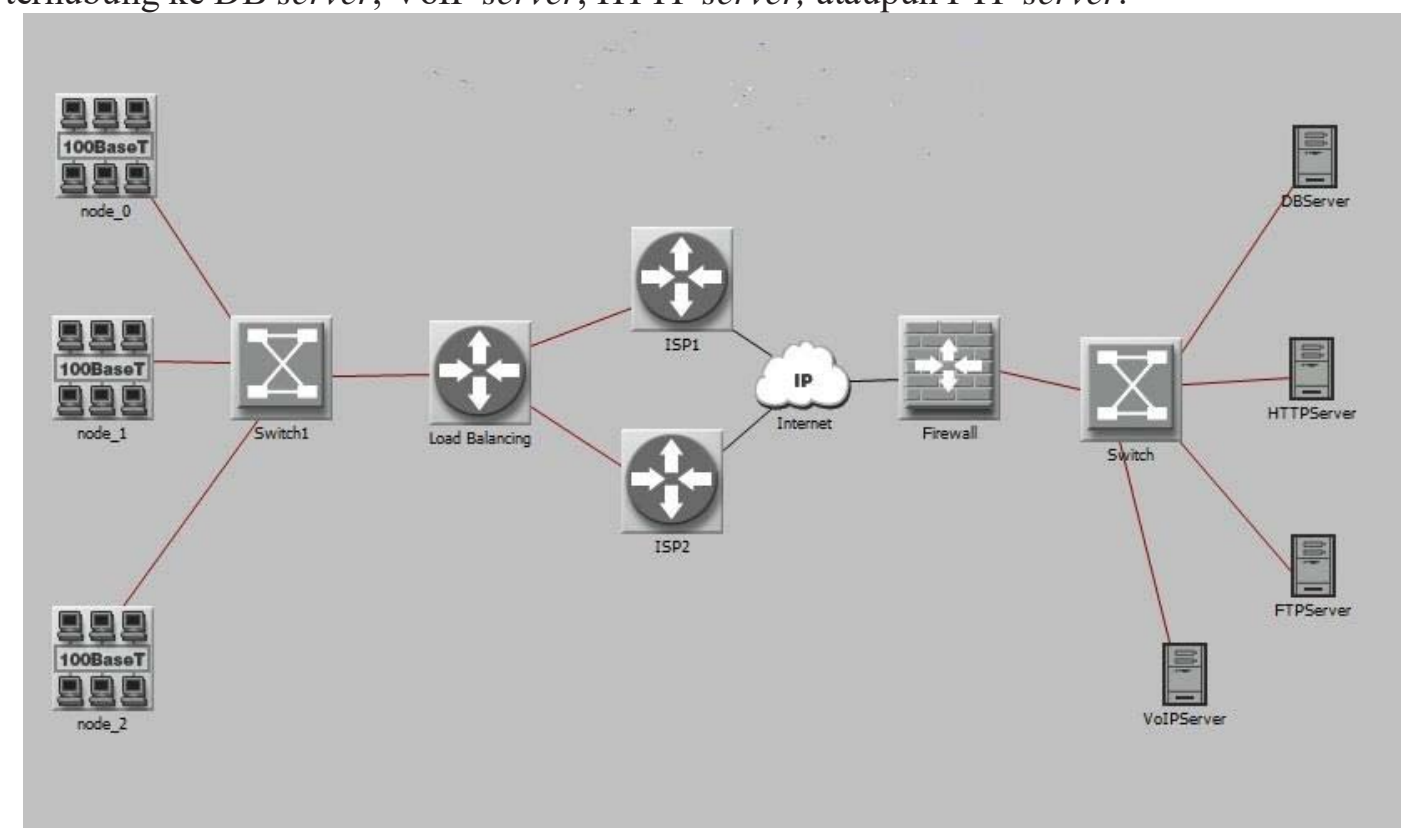

Gambar 4. Topologi Jaringan Load Balancing

Berikut adalah komponen jaringan dari Gambar 4:

a. Workstation, merupakan komputer PC yang digunakan sebagai client. Workstation bertugas untuk mengakses aplikasi-aplikasi yang terdapat pada masing-masing server.

b. Router, perangkat ini berfungsi sebagai penghubung antar jaringan-jaringan yang berbeda. Router bertugas sebagai jembatan dua buah ISP untuk mengatur jaringan komputer. ISP-1 dengan kapasitas bandwidth 4 Mbps dan ISP-2 dengan kapasitas bandwidth 1 Mbps.

c. Internet, merupakan jaringan komputer publik.

d. Firewall, adalah perangkat yang berfungsi untuk memfilter paket yang masuk ke dalam jaringan tertentu, firewall dapat memilah-milah jenis paket dan tugasnya mengamankan suatu jaringan dari paket-paket yang tidak diinginkan.

e. Switch, merupakan penghubung beberapa perangkat untuk membentuk jaringan kecil atau Local Area Network (LAN).

f. Server, yang berfungsi sebagai perangkat untuk penyedia layanan dalam jaringan komputer.

\subsection{Simulasi Skenario}

9 buah skenario jaringan yang berbeda digunakan dalam lingkungan simulasi. Skenario 1, 2 dan 3 digunakan untuk mengkur pengaruh algoritma round robin terhadap jaringan load balancing. Skenario 4, 5 dan 6 mengukur pengaruh algoritma least connection terhadap jaringan load balancing. Skenario 7, 8 dan 9 mengukur pengaruh ratio terhadap jaringan load balancing. 
Tabel 1.

Skenario Load Balancing

\begin{tabular}{|c|c|c|c|}
\hline Skenario & $\begin{array}{c}\text { Algoritma } \\
\text { Load Balancing }\end{array}$ & $\begin{array}{c}\text { Besar } \\
\text { Data Uji }\end{array}$ & Keterangan \\
\hline Skenario 1 & \multirow{3}{*}{ Round Robin } & $1 \mathrm{Mbps}$ & \multirow{9}{*}{$\begin{array}{l}\text { Metric Pengukuran: } \\
\text { - } \quad \text { Throughput } \\
\text { - } \quad \text { Delay } \\
\text { - } \quad \text { Jitter } \\
\text { Data Uji: } \\
\text { Transaksi workstation dengan } \\
\text { - } \quad \text { HTTP Server } \\
\text { - } \quad \text { DB Server } \\
\text { - } \quad \text { FTP Server } \\
\text { - } \quad \text { VoIP Server } \\
\text { Waktu Pengukuran: } \\
\text { 90 menit (diukur setelah jaringan } \\
\text { mencapai titikjenuh) }\end{array}$} \\
\hline Skenario 2 & & $5 \mathrm{Mbps}$ & \\
\hline Skenario 3 & & $7 \mathrm{Mbps}$ & \\
\hline Skenario 4 & \multirow{3}{*}{ Least Connection } & $1 \mathrm{Mbps}$ & \\
\hline Skenario 5 & & $5 \mathrm{Mbps}$ & \\
\hline Skenario 6 & & $7 \mathrm{Mbps}$ & \\
\hline Skenario 7 & \multirow{3}{*}{ Ratio } & $1 \mathrm{Mbps}$ & \\
\hline Skenario 8 & & $5 \mathrm{Mbps}$ & \\
\hline Skenario 9 & & $7 \mathrm{Mbps}$ & \\
\hline
\end{tabular}

\subsection{Simulasi Jaringan Data}

Penelitian mengukur pengaruh transaksi data HTTP, VoIP, FTP dan DB terhadap jaringan load balancing. Pengukuran dilakukan dalam berbagai skenario yang berbeda berdasarkan algoritma round robin, least connection dan ratio. Parameter perbandingan yang diukur adalah:

1. Throughput

Throughput yang diukur adalah throughput masuk keseluruhan

2. Delay

Delay yang diukur berdasarkan komunikasi antara VoIP_src dengan VoIP_dst

3. Jitter

Jitter yang diukur berdasarkan komunikasi antara VoIP_src dengan VoIP_dst

\section{Pengujian}

\subsection{Perbandingan Keseluruhan Load Balancing}

Berikut adalah tabel keseluruhan dari simulasi algoritma Round Robin, Least Connection dan Ratio dengan rataan uji data $1 \mathrm{Mbps}, 5 \mathrm{Mbps}$ dan $7 \mathrm{Mbps}$. Setiap percobaan menghasilkan pengukuran throughput, end-to-end delay dan jitter.

Tabel 2.

Hasil Simulasi Perbandingan Rata-Rata Keseluruhan Jaringan Load Balancing

\begin{tabular}{|l|r|r|r|}
\hline \multirow{2}{*}{ Faktor Pengukuran } & \multicolumn{3}{|c|}{ Average Data 1 Mbps } \\
\cline { 2 - 4 } & Round Robin & Least Connection & \multicolumn{1}{c|}{ Ratio } \\
\hline Throughput (Kbps) & 897 & $\mathbf{9 6 0}$ & 948 \\
\hline End-to-End Delay (ms) - VoIP & 738 & 336 & $\mathbf{3 2 9}$ \\
\hline Jitter (ms) - VoIP & 0.041 & 0.031 & $\mathbf{0 . 0 2 0}$ \\
\hline \multirow{2}{*}{ Faktor Pengukuran } & \multicolumn{3}{|c|}{ Average Data 5 Mbps } \\
\cline { 2 - 4 } & Round Robin & Least Connection & \multicolumn{1}{|c|}{ Ratio } \\
\hline Throughput (Kbps) & 3660 & $\mathbf{3 7 5 1}$ & 3703 \\
\hline End-to-End Delay (ms) - VoIP & $\mathbf{3 7 1}$ & 406 & 426 \\
\hline Jitter (ms) - VoIP & 0.006 & 0.047 & $\mathbf{0 . 0 0 2}$ \\
\hline
\end{tabular}




\begin{tabular}{|l|r|r|r|}
\hline \multirow{2}{*}{ Faktor Pengukuran } & \multicolumn{3}{|c|}{ Average Data 7 Mbps } \\
\cline { 2 - 4 } & Round Robin & Least Connection & \multicolumn{1}{c|}{ Ratio } \\
\hline Throughput (Kbps) & 3802 & $\mathbf{4 0 7 1}$ & 3986 \\
\hline End-to-End Delay (ms) - VoIP & $\mathbf{4 1 5}$ & 463 & 423 \\
\hline Jitter (ms) - VoIP & 0.016 & 0.015 & $\mathbf{0 . 0 1 4}$ \\
\hline
\end{tabular}

Berdasarkan Tabel 2, dimana semua skenario dibandingkan, maka hasil yang di peroleh sebagai berikut:

1) Algoritma Load Balancing terbaik untuk skenario uji data 1 Mbps:
a) Throughput
: Least Connection
b) End-to-end Delay $\quad$ : Ratio
c) Jitter
: Ratio

2) Algoritma Load Balancing terbaik untuk skenario uji data 5 Mbps:
a) Throughput
: Least Connection
b) End-to-end Delay
: Round Robin
c) Jitter
: Ratio

3) Algoritma Load Balancing terbaik untuk skenario uji data 7 Mbps:
a) Throughput
: Least Connection
b) End-to-end Delay
: Round Robin
c) Jitter
: Ratio

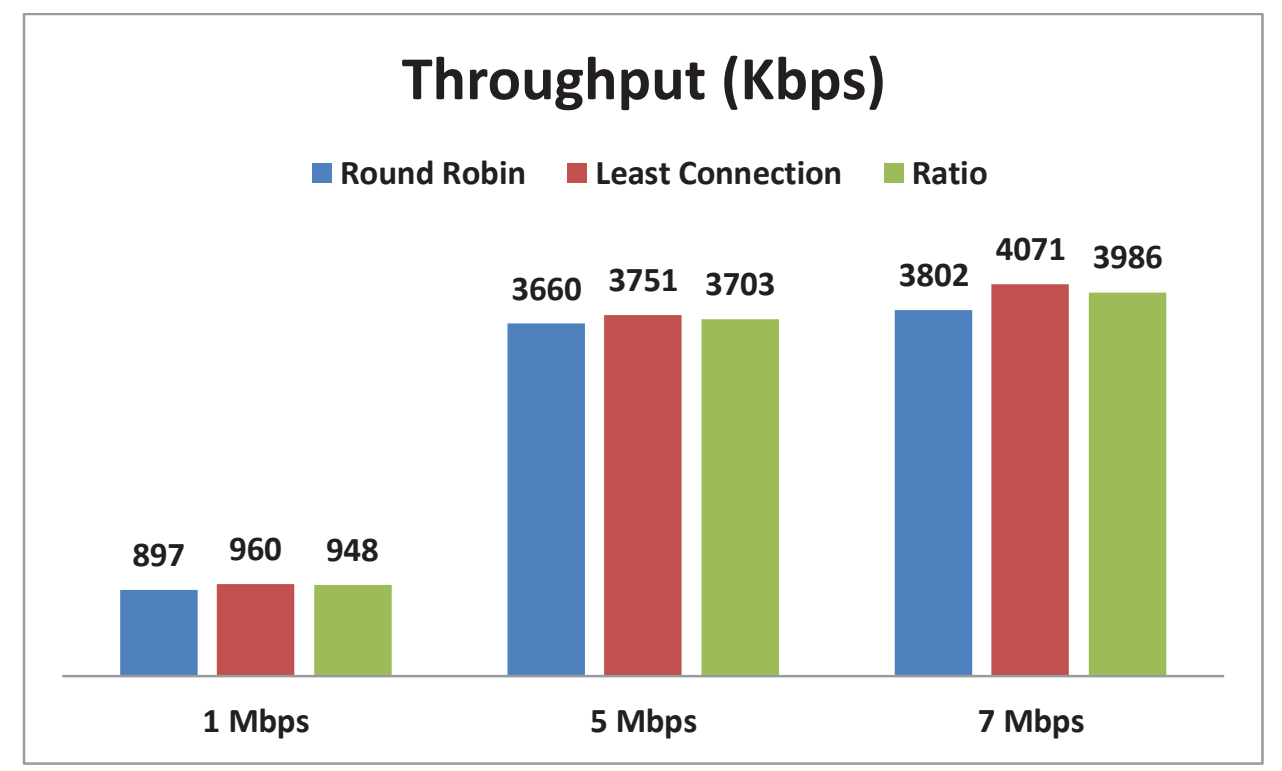

Gambar 5. Grafik throughput keseluruhan

Gambar 5 menggambarkan bahwa Least Connection menghasilkan throughput paling tinggi dibandingkan Ratio dan Round Robin. Round Robin menghasilkan nilai paling rendah, sehingga Round Robin tidak disarankan untuk kebutuhan koneksi yang membutuhkan throughput tinggi. 


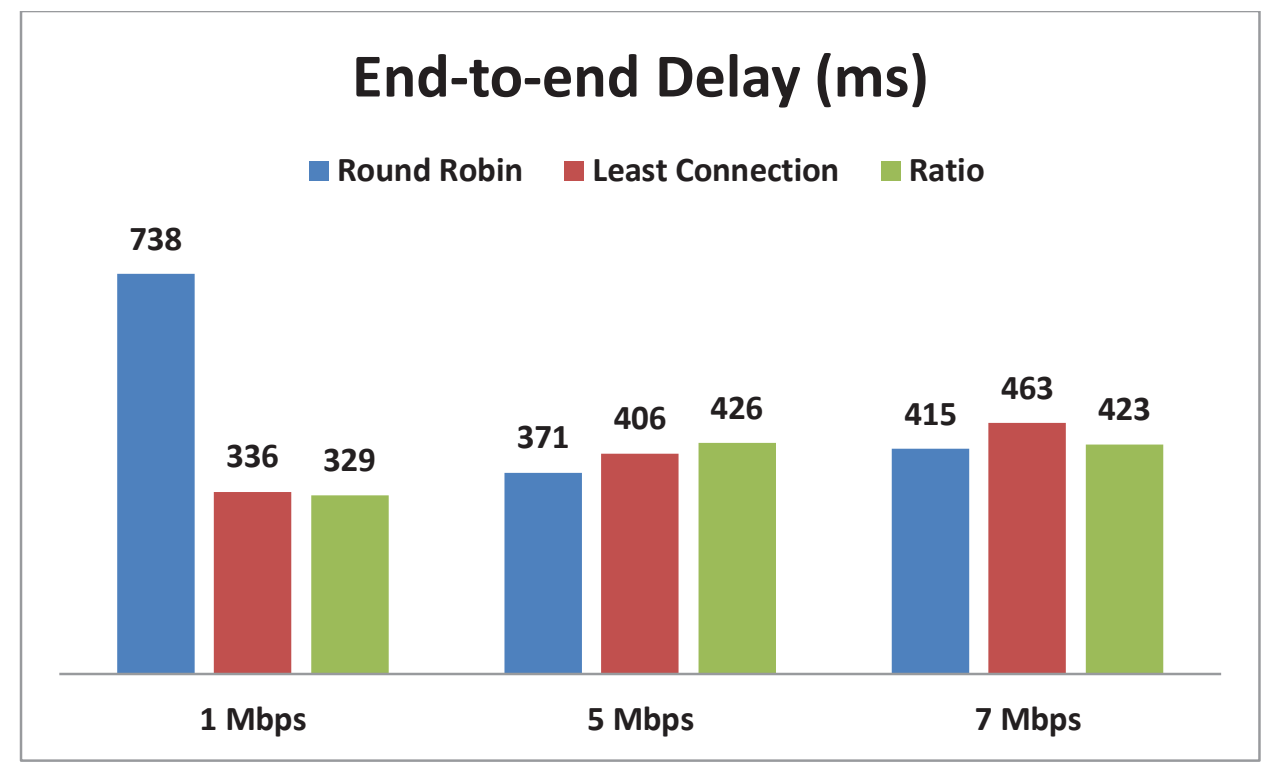

Gambar 6. Grafik delay keseluruhan

Gambar 6 menggambarkan Ratio paling efisien dalam hal delay untuk skenario 1 Mbps, akan tetapi Round Robin lebih kecil dan paling efisien pada skenario 5 Mbps dan 7 Mbps. Hanya saja pada skenario 1 Mbps, Round Robin ternyata memiliki delay paling besar, sehingga stabilitasnya tidak cukup baik. Ratio disarankan sebagai solusi jika diperlukan koneksi dengan delay yang efisien dan stabil.

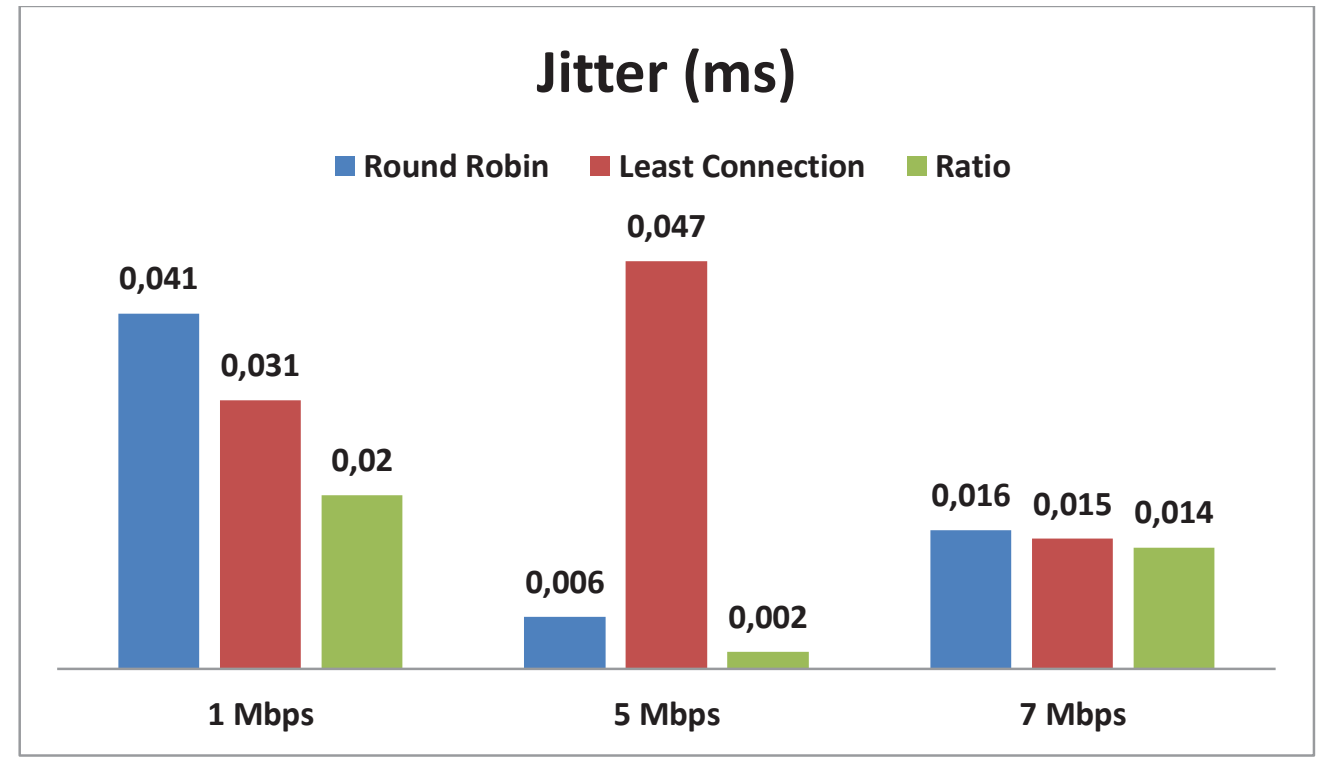

Gambar 7. Grafik jitter keseluruhan

Gambar 7 memperlihatkan dengan mutlak bahwa Ratio memiliki variansi delay (jitter) yang paling kecil, sehingga dapat dikatakan paling stabil dalam hal penanganan jitter. Ratio direkomendasikan menjadi solusi untuk koneksi yang memerlukan jitter yang rendah (delay stabil).

\section{Kesimpulan}

Kesimpulan dari penelitian yang telah dilakukan adalah sebagai berikut:

1. OPNET Modeler dapat melakukan pemodelan dan simulasi jaringan load balancing, sehingga dapat dihasilkan data perbandingan kinerja dari berbagai algoritma load balancing. Hasil pengukuran kinerja algoritma load balancing secara umum menunjukkan bahwa Ratio lebih baik dibandingkan dengan Least Connection atau Round Robin, hal ini terlihat dari angka pengukuran parameter End-to-end Delay dan Jitter yang paling baik ditemukan pada Ratio.

2. Pemilihan algoritma load balancing untuk implementasi di kasus nyata: 
a) Ratio baik digunakan untuk jaringan internet yang memerlukan jitter dan end-to-end delay yang paling efisien.

b) Least Connection baik digunakan untuk jaringan internet yang memerlukan throughput yang paling maksimal.

\section{Daftar Pustaka}

Anton, W. (1997). Jaringan Komputer. Bandung: Informatika.

DELL inc. (2015). SRA Load Balancing and High Availability. Retrieved 2015, from http://www.sonicwall.com: http://www.sonicwall.com/de/de/products/326.html

Ellrod, C. (2010). Load Balancing - Round Robin. Retrieved 2015, from http://blogs.citrix.com: http://blogs.citrix.com/2010/09/03/load-balancing-round-robin/

Haryadi, S. (2010). Quality of Service (QoS) Dan Pengukurannya.

Kopparapu, C. (2002). Load Balancing Servers, Firewalls, and Caches. John Wiley \& Sons, Inc.

Kurniawan, H. (2011). ANALISIS KINERJA BEBERAPA ALGORITMA LOAD BALANCING . Jurnal Seminar Nasional Informatika UPN.

OPNET. (2012, Juni 5). (OPNET) Retrieved September 2, 2014, from www.opnet.com: https://support.riverbed.com/bin/support/static//doc/opnet/17.5.A/online/modeler_17.5_PL5/Tutorials/ wwhelp/wwhimpl/common/html/wwhelp.htm\#context=tutorials\&file=tut_com_intro.html

Saputra, A. R. (2013). ANALISA PERBANDINGAN METODE LOAD BALANCING PEER CONNECTION CLASSIFIER (PCC) DENGAN NTH PADA ROUTER MIKROTIK. Jurnal Skripsi Tekhnologi Informatika UIN. 